\title{
Glaucoma Awareness and Knowledge, and Attitude to Screening, in a Rural Community in Ebonyi State, Nigeria
}

\author{
C. E. Ogbonnaya ${ }^{1}$, L. U. Ogbonnaya ${ }^{2}$, O. Okoye ${ }^{3 *}$, N. Kizor-Akaraiwe ${ }^{4}$ \\ ${ }^{1}$ Department of Ophthalmology, Federal Teaching Hospital, Abakaliki, Nigeria \\ ${ }^{2}$ Department of Community Medicine, Federal Teaching Hospital, Abakaliki, Nigeria \\ ${ }^{3}$ Department of Ophthalmology, University of Nigeria Teaching Hospital, Enugu, Nigeria \\ ${ }^{4}$ Department of Ophthalmology, College of Medicine, Enugu State University of Science and Technology, Enugu, \\ Nigeria \\ Email: "eagleobi@yahoo.com
}

Received 22 April 2016; accepted 28 May 2016; published 31 May 2016

Copyright (C) 2016 by authors and Scientific Research Publishing Inc.

This work is licensed under the Creative Commons Attribution International License (CC BY). http://creativecommons.org/licenses/by/4.0/

(c) (i) Open Access

\begin{abstract}
Awareness, knowledge, beliefs and the sociocultural and religious practices, are believed to influence the treatment-seeking behavior of people as well as their uptake of services. This study was carried out to assess the awareness and knowledge about glaucoma, and the attitude to glaucoma screening in Nchokko village in Igbeagu community, Izzi Local Government Area, Ebonyi State, Nigeria. This was a cross-sectional descriptive study. Data were collected using an interviewer-administered questionnaire and analyzed using SPSS 22. Results show that a total of 402 respondents-228 (56.7\%) women and $174(43.3 \%)$ men-were interviewed. The mean age of respondents was $31.7 \pm 11.9$ years; $82.8 \%$ of the respondents had secondary education or less; $53 \%$ were married; and $38.1 \%$ were farmers. Only $21.1 \%$ of the respondents were aware of glaucoma. Gender, education, and positive family history were significantly associated with awareness. Only $6.3 \%$ of the respondents had good knowledge about the disease. A large proportion of respondents $(62.1 \%)$ exhibited a positive attitude towards glaucoma screening; however, only $5 \%$ had ever undergone glaucoma screening. We conclude that glaucoma awareness and knowledge were poor in this rural community, but a high proportion of respondents had a positive attitude towards glaucoma screening. We therefore recommend a focused community health education campaign that will raise awareness and impart adequate knowledge about glaucoma. Eye care providers should make use of every opportunity to convey information on glaucoma to patients.
\end{abstract}

\section{Keywords}

Glaucoma Awareness and Knowledge, Screening, Nchokko-Igbeagu Izzi, Ebonyi State, Nigeria

\footnotetext{
${ }^{*}$ Corresponding author.
}

How to cite this paper: Ogbonnaya, C.E., Ogbonnaya, L.U., Okoye, O. and Kizor-Akaraiwe, N. (2016) Glaucoma Awareness and Knowledge, and Attitude to Screening, in a Rural Community in Ebonyi State, Nigeria. Open Journal of Ophthalmology, 6, 119-127. http://dx.doi.org/10.4236/ojoph.2016.62017 


\section{Introduction}

Glaucoma is a disease characterized by atrophy of the optic nerve and progressive loss of vision. It is an important public health problem, being the commonest cause of irreversible blindness in the world [1] [2]. In Nigeria, it has been found to be responsible for $16 \%$ of the blindness among the population aged 40 years and above [3]. Estimates by Quigley and Broman [2] suggest an increase in the burden of the disease worldwide between the years 2010 and 2020.

The commonest form of this disease-open-angle glaucoma-usually has an insidious onset, which may explain why most glaucoma patients present late. It has been estimated that more than half of glaucoma patients are already blind in at least one eye at presentation in Africa [4]-[6]. In Ebonyi State, Ogbonnaya [6] found that $53 \%$ of glaucoma patients were already blind (i.e., best-corrected visual acuity < 3/60) at presentation. Yet, blindness from glaucoma is preventable if detected early and managed appropriately. Early detection and prompt treatment are only achieved by timely eye examinations [5] [6].

Awareness, knowledge, and beliefs regarding diseases, as well as socio-cultural and religious practices, affect the treatment-seeking behavior of people and the uptake of services [7] [8]. If glaucoma prevention services and treatment programs are available, an informed public is more likely to take advantage of it before significant functional disability or irreversible vision loss occurs [9].

This study therefore aimed at assessing how glaucoma awareness and knowledge affect attitudes and practices among the population in Nchokko village in Igbeagu community of Izzi Local Government Area (LGA) of Ebonyi State, Nigeria. This information can be of great value when planning health education campaigns related to glaucoma and can benefit other prevention of blindness activities in this population residing in the catchment area covered by our community eye program.

\section{Materials and Methods}

\subsection{Study Area}

Ebonyi is one of the relatively younger states in Nigeria, having been created out of Enugu and Abia states in 1996. It has a population of approximately 2.4 million people. The Nchokko village Igbeagu Community in Izzi LGA of Ebonyi State was the location of the study. The Igbeagu community is one of the newly created development centers in Izzi LGA. It is about $20 \mathrm{~km}$ from Abakaliki, the state capital. Four out of the 25 villages in Izzi LGA make up the development center. All the four villages are served by the Ebonyi State University Teaching Hospital Primary Health Care Center. The people of Igbeagu are agrarian, growing mainly root crops, tubers, and grains, especially rice.

The Igbeagu Development Center was purposively selected for this study; the reasons were as follows:

- The Department of Community Medicine of the Ebonyi State University (EBSU) has the development center as its primary health care (PHC) practice area for providing training to resident doctors and medical students.

- The Department of Ophthalmology of EBSU also uses the PHC for its community ophthalmology programs.

- The study was designed as part of efforts to improve ophthalmic services to this rural area.

\subsection{Study Design}

This was a cross-sectional descriptive study.

\subsection{Sample Size and Sampling Technique}

The sample size was calculated using the formula for estimating proportion $\left(n=Z^{2} * P Q / d^{2}\right)$. At $\alpha=0.05$ and power of $90 \%$, a minimum sample size of 372 was calculated using $P$ of $41.2 \%$ from awareness of glaucoma from a previous study [9]. Because the total number of adults/adolescents in the community was only 435, the entire population was invited to participate in the study; 402 persons consented.

\subsection{Study Instrument and Data Collection}

The study instrument was a pretested interviewer-administered questionnaire that elicited information on respondents' socio-demographic characteristics, awareness of glaucoma, level of knowledge about glaucoma, and attitudes and practices with regard to glaucoma screening. Awareness of glaucoma was defined as "having heard 
of glaucoma"; respondents were asked if they had ever heard of glaucoma and, if so, what their source of information was. The level of knowledge regarding glaucoma was assessed on the basis of the responses to the following questions:

1) Glaucoma is a blinding eye disease: Yes/No

2) Glaucoma often causes high pressure in the eye: Yes/No

3) Glaucoma can occur without symptoms: Yes/No

4) Glaucoma runs in families: Yes/No

5) Old age is a risk factor: Yes/No

6) High blood pressure is a risk factor: Yes/No

7) Diabetes mellitus is a risk factor: Yes/No

8) Black race is a risk factor: Yes/No

9) White race is a risk factor: Yes/No

10) Glaucoma is a family curse: Yes/No

11) Glaucoma results from poor feeding: Yes/No

12) Glaucoma results from poison: Yes/No

Each correct answer to the above questions was scored 1 and a wrong answer was scored 0 , and the total was used as a measure of the respondent's overall knowledge regarding glaucoma. A respondent could thus score a maximum of 12 and a minimum of 0 . We graded a score of $0-5$ as "poor knowledge" and a score of $6-12$ as "good knowledge".

To measure attitude to glaucoma screening, respondents were asked if they thought that they needed glaucoma screening. An affirmative response was taken as indicative of a positive attitude to glaucoma screening.

To measure practice of glaucoma screening, respondents were asked if they had ever had a routine eye examination by an ophthalmologist (as opposed to an eye examination prompted by the presence of some visual symptom). A positive answer was taken as indication that the respondent had undergone glaucoma screening

\subsection{Data Management and Analysis}

IBM SPSS statistics for Windows, Version 20.0 (IBM Corp., Armonk, NY, USA) was used for data analysis. Frequency tables and charts were used for descriptive statistics. Bivariate analysis was performed to assess the relationships between the various socio-demographic variables as independent variables, and glaucoma awareness, glaucoma knowledge, and glaucoma screening practice as dependent variables. The relationship between glaucoma awareness and knowledge as independent variables, and glaucoma screening practice as the dependent variable was also examined. The chi-square test was used to assess the strength of association between these categorical variables. Significance was set at $p \leq 0.05$ for all tests. During data analysis, neutral responses such as "not sure" or undecided were regarded as negative answer.

\subsection{Ethical Approval}

Ethical approval for this study was obtained from the Research Ethics Committee of the Federal Teaching Hospital, Abakaliki. The purpose of the study was adequately explained to members of the community, and refusal of participation by any respondent was respected. All efforts were made to ensure confidentiality of data by removing every personal identifier.

\section{Limitations of the Study}

The selection of the location of this study was purposive, and the village was a small settlement. Despite the fact that Nchokko is typical of the rural villages in Ebonyi State, the results may not be immediately generalizable. Secondly, data on routine eye check are self reports and should be interpreted with caution.

\section{Results}

A total of 402 persons-228 (56.7\%) women and 174 (43.3\%) men—participated in the survey. The mean age of the respondents was $31.7 \pm 11.9$ years (range, 11 - 75 years). The majority 249 (61.9\%) were in the age-group of 21 - 40 years. A high proportion (82.8\%) had secondary education or less. The commonest religion was Christianity (89.8\%). More than half (53\%) of the respondents were married, and the majority (38.1\%) were 
farmers. Of the 402 respondents, 10 (2.5\%) indicated that they were glaucoma patients, while 63 (15.7\%) had a positive family history of blindness. Furthermore, 93 (23.1\%) respondents were using spectacles (Table 1 ).

Table 1. Socio-demographic characteristics of respondents.

\begin{tabular}{|c|c|c|}
\hline Characteristics & Frequency & Percentage \\
\hline \multicolumn{3}{|l|}{ Gender } \\
\hline Male & 174 & 43.3 \\
\hline Female & 228 & 56.7 \\
\hline \multicolumn{3}{|l|}{ Age-group } \\
\hline $11-20$ & 70 & 17.4 \\
\hline $21-30$ & 153 & 38.1 \\
\hline $31-40$ & 96 & 23.9 \\
\hline $41-50$ & 57 & 14.2 \\
\hline $51-60$ & 19 & 4.7 \\
\hline$>60$ & 7 & 1.7 \\
\hline \multicolumn{3}{|l|}{ Educational level } \\
\hline Primary & 137 & 34.1 \\
\hline Secondary & 165 & 41.0 \\
\hline Tertiary & 31 & 7.7 \\
\hline No formal education & 69 & 17.2 \\
\hline \multicolumn{3}{|l|}{ Religion } \\
\hline Christianity & 361 & 89.8 \\
\hline African traditional & 35 & 8.7 \\
\hline Islam & 5 & 1.2 \\
\hline Other & 1 & 0.2 \\
\hline \multicolumn{3}{|l|}{ Marital status } \\
\hline Married & 213 & 53.0 \\
\hline Single & 156 & 38.8 \\
\hline Widow & 29 & 7.2 \\
\hline Widower & 4 & 1.0 \\
\hline \multicolumn{3}{|l|}{ Occupation } \\
\hline Farming & 153 & 38.1 \\
\hline Civil servant & 86 & 21.4 \\
\hline Businessman/Trader & 58 & 14.4 \\
\hline Public servant (private sector) & 37 & 9.2 \\
\hline Artisan/Apprentice & 35 & 8.7 \\
\hline Health worker & 20 & 5.0 \\
\hline Student & 13 & 3.2 \\
\hline \multicolumn{3}{|l|}{ Do you suffer from glaucoma? } \\
\hline Yes & 10 & 2.5 \\
\hline No & 75 & 18.7 \\
\hline Not sure & 317 & 78.9 \\
\hline \multicolumn{3}{|l|}{ Positive family history of blindness } \\
\hline Yes & 63 & 15.7 \\
\hline No & 296 & 73.6 \\
\hline Not sure & 43 & 10.7 \\
\hline
\end{tabular}




\subsection{Glaucoma Awareness}

The majority 317 (78.9\%) of respondents had never heard of glaucoma. For the 85 respondents who were aware of glaucoma, the source of information was mostly the mass media for 36 (42.4\%) and health facilities for 25 (29.4\%) of them. Other sources of information were school 11 (12.9\%), friends/relations with glaucoma 5 (5.9\%), and other unspecified sources 8 (9.4\%).

\subsection{Knowledge of Symptoms of Glaucoma}

With regard to knowledge of different symptoms of glaucoma, 56 (13.9\%) respondents knew that glaucoma is a blinding eye disease, 26 (6.5\%) knew that it can occur without symptoms, and 17 (4.2\%) knew that glaucoma is associated with high pressure in the eye (Table 2).

Table 2. Knowledge of glaucoma.

\begin{tabular}{|c|c|c|}
\hline & Frequency & Percentage \\
\hline \multicolumn{3}{|l|}{ A. Knowledge of symptoms } \\
\hline \multicolumn{3}{|c|}{ Glaucoma is a blinding eye disease } \\
\hline Yes & 56 & 13.9 \\
\hline No & 346 & 86.1 \\
\hline \multicolumn{3}{|c|}{ Glaucoma occurs without symptoms? } \\
\hline Yes & 26 & 6.4 \\
\hline No & 376 & 93.6 \\
\hline \multicolumn{3}{|c|}{ Glaucoma is often associated with high pressure in the eye } \\
\hline Yes & 17 & 4.2 \\
\hline No & 385 & 95.8 \\
\hline \multicolumn{3}{|l|}{ B. Knowledge of risk factors } \\
\hline \multicolumn{3}{|c|}{ Glaucoma is more common among the black race } \\
\hline Yes & 32 & 8.0 \\
\hline No & 370 & 92.0 \\
\hline \multicolumn{3}{|c|}{ Glaucoma "runs" in families } \\
\hline Yes & 45 & 11.2 \\
\hline No & 357 & 88.8 \\
\hline \multicolumn{3}{|c|}{ Old age is a risk factor } \\
\hline Yes & 51 & 12.7 \\
\hline No & 24 & 6.0 \\
\hline Not sure & 327 & 81.3 \\
\hline \multicolumn{3}{|c|}{ High blood pressure is a risk factor } \\
\hline Yes & 25 & 6.2 \\
\hline No & 26 & 6.5 \\
\hline Not sure & 351 & 87.3 \\
\hline \multicolumn{3}{|c|}{ Diabetes mellitus is a risk factor } \\
\hline Yes & 20 & 5.0 \\
\hline No & 382 & 95.0 \\
\hline \multicolumn{3}{|c|}{ Glaucoma is more common among the 'white' race } \\
\hline Yes & 26 & 6.5 \\
\hline No & 376 & 93.5 \\
\hline \multicolumn{3}{|l|}{ C. Overall knowledge } \\
\hline Poor knowledge & 375 & 93.3 \\
\hline Good knowledge & 27 & 6.7 \\
\hline
\end{tabular}


With regard to knowledge of risk factors for glaucoma, 51 (12.7\%) respondents related glaucoma with old age, 45 (11.2\%) knew that glaucoma can "run” in families, 25 (6.2\%) knew that high blood pressure is a risk factor, and 20 (5.0\%) knew that diabetes mellitus is a risk factor (Table 2).

\subsection{Level of Knowledge of Glaucoma}

With regard to overall knowledge of glaucoma, only 27 (6.7\%) had good knowledge; the majority (375 respondents; 93.3\%) had poor knowledge (Table 2).

\subsection{Attitude to Glaucoma Screening}

Generally, 246 respondents (61.2\%) affirmed that they needed glaucoma screening; 156 (38.8\%) did not think they need screening (Table 3). However, amongst the 85 respondents who were aware of glaucoma, 60 (70.6\%) respondents had a positive attitude to glaucoma screening.

\subsection{Practice of Glaucoma Screening}

Generally, only 58 (14.4\%) respondents had ever undergone an eye examination by an ophthalmologist. Out of these, 35 (60.3\%) eye examinations were prompted by eye symptoms; only 23 (39.7\%) were routine (Table 3 ). Interestingly, all of these 23 were among those aware of glaucoma.

\subsection{Influence of Socio-Demographic Factors on Awareness, Knowledge, and Attitude towards Routine Eye Screening}

Age had no significant influence on glaucoma awareness, overall knowledge, attitude to screening, and practice of glaucoma screening in this community. On the other hand, education had significant influence on glaucoma awareness, with respondents with $\geq$ secondary education being more likely than those with $\leq$ primary education to be aware of glaucoma $\left(\mathrm{X}^{2}=7.30 ; p=0.007\right)$ and to have a positive attitude towards glaucoma screening $\left(\mathrm{X}^{2}\right.$ $=4.67 ; p=0.03)$. Surprisingly, level of education had no significant relationship with overall knowledge regarding glaucoma $\left(\mathrm{X}^{2}=0.44 ; p=0.5\right)$ or with practice of glaucoma screening $\left(\mathrm{X}^{2}=0.12 ; p=0.73\right.$; Table 4$)$.

Gender had a significant relationship with awareness, overall knowledge of glaucoma, and practice of glaucoma screening but not with attitude to glaucoma screening. Thus, men were more likely to be aware of glaucoma (29.3\% men vs. $14.9 \%$ women; $\left.\mathrm{X}^{2}=12.27 ; p<0.001\right)$ but, in contrast, females were more likely to have good knowledge of glaucoma $(9.2 \%)$ women vs. 3.5\% men; $\left.X^{2}=4.35 ; p=0.04\right)$. However, routine eye examination for glaucoma screening was significantly more common among men $\left(18.9 \%\right.$ men vs. $10.9 \%$ women; $\mathrm{X}^{2}=$ 4.49; $p=0.03$; Table 4).

Positive family history of glaucoma had a significant relationship with awareness $\left(\mathrm{X}^{2}=28.8 ; p=0.004\right)$ and knowledge $\left(\mathrm{X}^{2}=7.73 ; p=0.05\right)$ of glaucoma.

Knowledge of glaucoma was significantly related to attitude towards glaucoma screening.

\section{Discussion}

Awareness of glaucoma was found to be very poor in this population, with only $21.1 \%$ of respondents being

Table 3. Glaucoma screening.
\begin{tabular}{|ccc|}
\hline A. Attitude to glaucoma screening & & \\
\hline Do you think that you need glaucoma screening? & & \\
Yes & 246 & 61.2 \\
No & 156 & 38.8 \\
\hline B. Practice of glaucoma screening & & \\
\hline Have you ever had your eyes examined by an eye doctor? & & \\
Yes & 58 & 14.4 \\
No & 354 & 85.6 \\
Why were your eyes examined? (n = 58) & 20 & 34.5 \\
Routine & 38 & 65.5 \\
\hline Prompted by symptoms & & \\
\hline
\end{tabular}


Table 4. Relationship between socio-demographic variables and glaucoma knowledge, attitude, and practice of glaucoma screening.

\begin{tabular}{|c|c|c|c|c|}
\hline \multirow{2}{*}{ Variable } & \multicolumn{2}{|c|}{ Glaucoma awareness } & \multirow{2}{*}{ Total } & \multirow{2}{*}{$X^{2} ; p$ value } \\
\hline & Yes (\%) & No (\%) & & \\
\hline \multicolumn{5}{|l|}{ A. Gender } \\
\hline Male & $51(29.3)$ & $123(70.7)$ & 174 & $X^{2}=12.27$ \\
\hline Female & 34 (14.9) & $194(85.1)$ & 228 & $p<0.01$ \\
\hline \multicolumn{5}{|l|}{ B. Education } \\
\hline$\leq$ Primary school & $32(15.5)$ & $174(84.5)$ & $206(100)$ & $X^{2}=7.30$ \\
\hline$\geq$ Secondary school & $53(27.0)$ & $143(73.0)$ & $196(100)$ & $p<0.01$ \\
\hline & \multicolumn{2}{|c|}{ Attitude to glaucoma screening } & & \\
\hline & Positive (\%) & Negative (\%) & & \\
\hline \multirow{4}{*}{$\begin{array}{c}\leq \text { Primary school } \\
\geq \text { Secondary school }\end{array}$} & $115(55.8)$ & $91(44.2)$ & $206(100)$ & $X^{2}=4.67$ \\
\hline & $131(66.8)$ & $65(33.2)$ & $196(100)$ & $p=0.03$ \\
\hline & \multicolumn{2}{|c|}{ Knowledge of glaucoma } & & \\
\hline & Good (\%) & Poor (\%) & & \\
\hline \multicolumn{5}{|l|}{ C. Gender } \\
\hline Male & $6(3.5)$ & $168(96.5)$ & $174(100)$ & $X^{2}=4.35$ \\
\hline \multirow[t]{3}{*}{ Female } & $21(9.2)$ & 207 (90.8) & $228(100)$ & $p=0.04$ \\
\hline & \multicolumn{2}{|c|}{ Ever been screened for glaucoma } & & \\
\hline & Yes (\%) & No (\%) & & \\
\hline Male & 33 (18.9) & $141(81.1)$ & $174(100)$ & $X^{2}=4.49$ \\
\hline Female & 25 (10.9) & 203 (89.1) & $228(100)$ & $p=0.03$ \\
\hline
\end{tabular}

aware of the disease. This finding is consistent with the findings of several earlier studies on glaucoma awareness and knowledge performed inpatients attending eye care services [5] [9] [10]-[14], in the general population [11] [15], and in glaucoma patients [12] [16]-[19]. Awareness has also been shown to be particularly poor in rural communities [6]-[8] [10] [11] and among respondents of non-European descent in a Canadian study [9]. The insidious nature of the disease is believed to be contributory to this poor awareness.

In our study, religion and age had no significant influence on glaucoma awareness. This is similar to the findings of Mbadugha et al. [19] in Lagos, Nigeria, and Prabhu et al. [20] in South India. It however differs from the findings of many other studies [7] [11] [17]; for example, in an urban population-based study, Dandona et al. [11] reported that people aged 30 years and above were significantly more likely to be aware of glaucoma.

Many earlier studies have found that women were more likely to report awareness of glaucoma than men [7] [9] [20]. However, we found the converse, with men being significantly $(p<0.001)$ more likely to be aware of glaucoma than women This might be because the commonest source of information reported in this study was the radio, and women's participation in community radio programming is known to be poor across West Africa [21].

Educational level, as expected, remains a key determinant of awareness [7] [11]. In this study, respondents with $\geq$ secondary education were significantly $(p<0.01)$ more likely to be aware of the disease than those with sprimary education. This finding is consistent with Landers et al. [7], who reported that respondents with higher educational level were 1.8 times more likely to report awareness of glaucoma than those with lower educational level.

The influence of positive family history on awareness was very significant in this study. As expected, respondents with relatives suffering from glaucoma were more likely to be aware of glaucoma and have good knowledge regarding the disease. This trend has been observed in most studies on awareness and knowledge of glaucoma [7] [11] [17] [19] [20] [22].

Knowledge of glaucoma was found to be poorer than awareness in this study, with only $6.3 \%$ of the respondents having good knowledge of the disease. Most respondents (86.1\%) did not even know that glaucoma is a blinding eye disease.

It was surprising to note that although awareness of glaucoma was higher in men, knowledge about glaucoma was significantly higher in women $(p<0.05)$. It is possible that though more males may have heard about the 
disease through the radio, it is usually women who go to hospitals with their children for general care or attend free eye outreach programs and thereby receive better health education and knowledge regarding specific diseases.

Positive family history of glaucoma had a significant relationship with good knowledge of the disease ( $p<$ 0.1 ). This is not surprising because of these respondents would have had personal experience with the challenges of the disease and its management.

There was no relationship between awareness of glaucoma and the level of knowledge regarding glaucoma in this study. This agrees with the report by Mbadugha and Onakoya [19] who observed that even among glaucoma patients on treatment, knowledge regarding the disease was inadequate. This finding highlights the need for appropriate focused community health education campaigns that will go beyond creating awareness and impart adequate knowledge regarding glaucoma to the populace. It is also important for doctors to use every opportunity to provide relevant information to patients to increase patients' knowledge about their disease.

Surprisingly, educational status was not found to be significantly related to knowledge regarding glaucoma in this study. This highlights the need to include eye health education into the school curriculum at various levels of education, perhaps as part of general studies.

There was a discrepancy between the proportion of respondents with a positive attitude towards glaucoma screening (61.2\%) and the proportion actually undergoing screening (5\%). This discrepancy persisted even among those who were aware of glaucoma. While $70.6 \%$ of them were willing to undergo glaucoma screening, only $27.1 \%$ had gone for routine eye screening. It has been suggested that since the disease is often symptomless, the motivation for routine glaucoma screening will only stem from good knowledge about the disease [5] [23], which was found to be very poor in this study.

\section{Conclusion and Recommendations}

To conclude, glaucoma awareness and knowledge were poor in this rural community; however, a high proportion of respondents had a positive attitude towards glaucoma screening.

We recommend appropriate focused community health education campaigns that will go beyond creating awareness and impart adequate knowledge of glaucoma to the general population. Eye care providers must use every opportunity to convey information on glaucoma to patients.

\section{References}

[1] Tielsch, J.M., Sommer, A., Katz, J., Royall, R.M., Quigley, H.A. and Javitt, J. (1996) Racial Variations in the Prevalence of Primary Open Angle Glaucoma. The Baltimore Eye Survey. JAMA: Journal of the American Medical Association, 266, 369-374. http://dx.doi.org/10.1001/jama.1991.03470030069026

[2] Quigley, H.A. and Broman, A.T. (2006) The Number of People with Glaucoma Worldwide in 2010 and 2020. British Journal of Ophthalmology, 90, 262-267. http://dx.doi.org/10.1136/bjo.2005.081224

[3] Nigerian Eye Survey Group (2005-2007) The Nigeria National Blindness and Low Vision Survey.

[4] Bowman, R.J.C. (2006) How to Manage Glaucoma in a Patient in Africa. Community Eye Health Journal, 19 , 38-39.

[5] Altangerel, U., Hema, S., Shetty, N., et al. (2009) Knowledge about Glaucoma and Barriers to Follow-Up Care in a Community Glaucoma Screening Programme. Canadian Journal of Ophthalmology, 44, 66-69.

http://dx.doi.org/10.3129/i08-175

[6] Ogbonnaya, C.E. (2012) Profile of Blindness and Low Vision at Ebonyi State University Teaching Hospital (EBSUTH) Abakaliki. EMJ, 11, 13-19.

[7] Landers, J.A., Franzco, I.G. and Franzco, S.L.G. (2002) Factors Affecting Awareness and Knowledge of Glaucoma among Patients Presenting to an Urban Emergency Department. Clinical and Experimental Ophthalmology, 30, 104109. http://dx.doi.org/10.1046/j.1442-6404.2002.00493.x

[8] Livingstone, P.M., Lee, S.E., Depaola, C., Carson, C., Guest, C. and Taylor, H.R. (1995) Knowledge of Glaucoma and Its Relationship to Self-Care Practices in a Population Sample. Australian and New Zealand Journal of Ophthalmology, 23, 37-41. http://dx.doi.org/10.1111/j.1442-9071.1995.tb01643.x

[9] Kukuh, N., Maberly, D., Bassett, K. and Courtright, P. (2006) Awareness of Eye Diseases and Risk Factors: Identifying Needs for Health Education and Promotion in Canada. Canadian Journal of Ophthalmology, 41, 617-623. http://dx.doi.org/10.1016/S0008-4182(06)80035-9

[10] Tenkir, A., Solomon, B. and Deribew, A. (2010) Glaucoma Awareness among People Attending Ophthalmic Outreach 
Services in Southwestern Ethiopia. BMC Ophthalmology, 10, 17. http://dx.doi.org/10.1186/1471-2415-10-17

[11] Dandona, R., Dandona, L., John, R.K., McCathy, C.A. and Rao, G.N. (2001) Awareness of Eye Diseases in a Population in Southern India. Bulletin of the World Health Organization, 79, 96-102.

[12] Saw, S.M., Gazzard, G., Forster, P.S., Devereux, J.G. and Wong, M.L. (2003) Awareness of Glaucoma and Health Beliefs of Patients Suffering Primary Acute Angle Glaucoma. British Journal of Ophthalmology, 87, 446-449. http://dx.doi.org/10.1136/bjo.87.4.446

[13] Costa, V.P., Spaeth, G.L., Smith, M., Uddoh, C., Vasconcellos, J.P.C. and José, N.K. (2006) Patient Education in Glaucoma: What Do Patients Know about Glaucoma? Arquivos Brasileiros de Oftalmologia, 69, 923-927. http://dx.doi.org/10.1590/S0004-27492006000600024

[14] Sudesh, S., Downes, S.M. and McDonnell, P.J. (1993) Audit of Patients’ Awareness of Ophthalmic Diagnoses. Quality in Health Care, 2, 175-178. http://dx.doi.org/10.1136/qshc.2.3.175

[15] Baker, H., Cousens, S.N. and Murdoch, I.E. (2010) Poor Public Health Knowledge about Glaucoma: Fact or Fiction? Eye, 24, 653-657. http://dx.doi.org/10.1038/eye.2009.155

[16] Green, J., Siddah, H. and Mudrock, I. (2002) Learning to Live with Glaucoma. A Qualitative Study of Diagnosis and Impact of Sight Loss. Social Science and Medicine, 55, 257-267. http://dx.doi.org/10.1016/S0277-9536(01)00169-1

[17] Sheldrick, J.H., Ng, C. and Austin, D.J. (1994) An Analysis of Referral Routes and Diagnostic Accuracy in Cases of Suspected Glaucoma. Ophthalmic Epidemiology, 1, 31-39. http://dx.doi.org/10.3109/09286589409071443

[18] Mafwiri, M., Bowman, R.J., Wood, M. and Kabiru, J. (2005) Primary Open-Angle Glaucoma Presentation at a Tertiary Unit in Africa: Intraocular Pressure Levels and Visual Status. Ophthalmic Epidemiology, 12, 299-302. http://dx.doi.org/10.1080/09286580500180572

[19] Mbadugha, C.A. and Onakoya, A.O. (2014) The Awareness, Perceptions and Experiences of Primary Open Angle Glaucoma Patients in Lagos Nigeria. Scientific Reports, 4, 7585. http://dx.doi.org/10.1038/srep07585

[20] Prabhu, M., Patil, S. and Kangokar, P. (2013) Glaucoma Awareness and Knowledge in a Tertiary Care Hospital in a Tier-2 City in South India. Journal of the Scientific Society, 40, 3-8. http://dx.doi.org/10.4103/0974-5009.109674

[21] Sathyamangalam, R., Paul, P.G., Baskaran, M., Hemamalini, A., Madan, R., Augustian, J., Prema, R. and Lingam, V. (2009) Determinants of Glaucoma Awareness and Knowledge in Urban Chennai. Indian Journal of Ophthalmology, 57, 355-360. http://dx.doi.org/10.4103/0301-4738.55073

[22] Fortune, F., Chungong, C. and Kessinger, A. (2011) Community Radio, Gender and ICTs in West Africa. Search for Common Good, Washington, DC.

[23] Adegbehingbe, B.O. and Bisiriyu, L.A. (2008) Knowledge, Attitude and Self Care Practices Associated with Glaucoma among Hospital Workers in Ile-Ife, Osun State, Nigeria. Tanzania Journal of Health Research, 10, 240-245. 